\title{
Effect of Different Catalyst Deposition Technique on Aligned Multiwalled Carbon Nanotubes Grown by Thermal Chemical Vapor Deposition
}

\author{
Mohamed Shuaib Mohamed Saheed, Norani Muti Mohamed, and Zainal Arif Burhanudin \\ Centre of Innovative Nanostructures and Nanodevices, Universiti Teknologi PETRONAS, Seri Iskandar, 31750 Tronoh, Perak, Malaysia \\ Correspondence should be addressed to Norani Muti Mohamed; noranimuti_mohamed@petronas.com.my
}

Received 25 December 2013; Revised 24 February 2014; Accepted 4 March 2014; Published 10 April 2014

Academic Editor: Shijun Liao

Copyright (C) 2014 Mohamed Shuaib Mohamed Saheed et al. This is an open access article distributed under the Creative Commons Attribution License, which permits unrestricted use, distribution, and reproduction in any medium, provided the original work is properly cited.

\begin{abstract}
The paper reported the investigation of the substrate preparation technique involving deposition of iron catalyst by electron beam evaporation and ferrocene vaporization in order to produce vertically aligned multiwalled carbon nanotubes array needed for fabrication of tailored devices. Prior to the growth at $700^{\circ} \mathrm{C}$ in ethylene, silicon dioxide coated silicon substrate was prepared by depositing alumina followed by iron using two different methods as described earlier. Characterization analysis revealed that aligned multiwalled carbon nanotubes array of $107.9 \mu \mathrm{m}$ thickness grown by thermal chemical vapor deposition technique can only be achieved for the sample with iron deposited using ferrocene vaporization. The thick layer of partially oxidized iron film can prevent the deactivation of catalyst and thus is able to sustain the growth. It also increases the rate of permeation of the hydrocarbon gas into the catalyst particles and prevents agglomeration at the growth temperature. Combination of alumina-iron layer provides an efficient growth of high density multiwalled carbon nanotubes array with the steady growth rate of $3.6 \mu \mathrm{m}$ per minute for the first 12 minutes and dropped by half after 40 minutes. Thicker and uniform iron catalyst film obtained from ferrocene vaporization is attributed to the multidirectional deposition of particles in the gaseous form.
\end{abstract}

\section{Introduction}

Synthesis of multiwalled carbon nanotubes (MWCNT) using various chemical vapor deposition (CVD) techniques has been employed to understand the mechanism of MWCNT growth. CVD technique offers many advantages over laser ablation and arc discharge, namely, higher yield and purity, and is the only method where MWCNT structure can be controlled [1]. CVD method can utilize any form of hydrocarbon source whether as liquid, solid, or gas using various substrates such as silicon, glass, silica, and alumina [2-5]. CVD also offers better control of growth parameters. High density MWCNT have been grown by thermal CVD method using ethylene as the hydrocarbon source and transition metals such as iron, nickel, or cobalt as the catalyst [6]. Even though the growth of MWCNT has been improved significantly with the help of intensive research and material characterization, the difficulty still remains when fabricating tailored devices for particular applications as the result of the uncontrollable nature of MWCNT growth. One of the main requirements for devices is to grow a well-aligned MWCNT array with uniform length and diameter. Among the various applications are field emitter displays [7], electronic devices [8], shydrogen storage [9], sensors [10], and fuel cell electrodes [11]. MWCNT growth mechanism is still being debated intensely in the scientific community. The general consensus among them is that the decomposed carbon diffuses and precipitates from metal nanoparticles. Subsequent carbon atoms which are added will grow into tubular structure which then stops when the carbon supply is discontinued. Nanosized particles are important as the growth seeds for MWCNT growth [1].

There are significant challenges in growing MWCNT on $\mathrm{Si}$ substrate. A direct coating of catalyst on Si substrate is thought to be detrimental for MWCNT growth. At elevated 
temperature, undesirable catalyst-substrate interaction will lead to the formation of silicide that can poison the catalyst [12]. Buffer layers such as thermally grown $\mathrm{SiO}_{2}, \mathrm{Al}_{2} \mathrm{O}_{3}$, and $\mathrm{TiO}_{2}$ were introduced to overcome this problem [13, 14]. These buffer layers increase the growth efficiency of nanotubes and modify the catalyst-substrate interaction. The thickness of catalyst layer also plays an important role in the alignment of MWCNT together with the buffer layer. Presence of oxygen in the catalyst is believed to promote the MWCNT growth since it can prevent the agglomeration of particles into larger particles [15]. Smaller particles can maintain the catalytic activity for a prolonged period of time.

This paper reported the growth of vertically aligned MWCNT array using thermal CVD technique by employing ferrocene vaporization as the method to deposit iron. Iron catalyst deposition using electron beam evaporation was also investigated in order to compare the quality of MWCNT produced. The two catalyst deposition techniques are compared in order to optimize the thickness of iron catalyst required for the growth of aligned MWCNT array. Alumina was introduced as the buffer layer and the chemical interactions between catalyst and substrate are discussed for better understanding of the growth of aligned MWCNT. Aligned MWCNT which are highly directional with uniform length and diameter are crucial for the development of the nanotubes-based devices.

\section{Materials and Methods}

Substrates of size $10 \mathrm{~mm} \times 10 \mathrm{~mm}$ were cut from the $\mathrm{p}$ doped Si (100) wafer with resistivity of $0.001-0.005 \Omega \mathrm{cm}$. The samples were cleaned by using Radio Corporation of America (RCA) method and oxidized in oxygen for 4 hours at $1100^{\circ} \mathrm{C}$ for the growth of $\mathrm{SiO}_{2}$ layer. The samples were then deposited with thin aluminum film using electron beam evaporation operated at vacuum pressure of $2 \times 10^{-3}$ Torr. Alumina layer was formed by oxidizing the aluminum coated samples in oxygen for one hour at $600^{\circ} \mathrm{C}$. This was followed by the deposition of iron catalyst by using two different techniques, electron beam evaporation in the evaporator and ferrocene vaporization in quartz chamber at $850^{\circ} \mathrm{C}$ for 10 minutes. The annealing of samples was carried out in oxygen for one hour at $400^{\circ} \mathrm{C}$ and the etching process was performed using ammonia gas as the etchant for 10 minutes with a flow rate of $10 \mathrm{sccm}$ at $850^{\circ} \mathrm{C}$. The growth of MWCNT was performed using thermal CVD system for 20 minutes with ethylene as the carbon source and diluted in hydrogen environment with a steady flow rate of $700 \mathrm{sccm}$ at $700^{\circ} \mathrm{C}$. Prior to the synthesis of MWCNT, the samples were treated in $\mathrm{H}_{2}$ environment for 4 minutes. At the end of growth process, the CVD system was cooled to room temperature in Ar ambient.

All samples were analyzed using field emission scanning electron microscope (FESEM), Zeiss Supra55 VP to determine the length, diameter and the surface morphology of MWCNT, and the structure of metal particles with energy dispersive X-ray (EDX) analysis for chemical composition. High resolution transmission electron microscopy
(HRTEM), Zeiss Libra 200 was conducted for internal structure analysis and Raman spectroscopy, and Horiba Jobin Yvon HR800 for the determination of the crystallinity of MWCNT with $514.53 \mathrm{~nm}$ wavelength from Ar laser light source. X-ray Photoelectron Spectroscopy (XPS) Thermo Scientific K- $\alpha$ was used to study the chemical interactions and transformations between substrate and catalyst during each process for a better understanding of MWCNT growth.

\section{Results and Discussion}

FESEM images of thermally grown $\mathrm{SiO}_{2}$ film and the deposited iron by electron beam evaporation and ferrocene vaporization are shown in Figure 1. The thickness of $\mathrm{SiO}_{2}$ film recorded from the image is about $560 \mathrm{~nm}$ (Figure 1(a)). After the heating process on the aluminum coated substrate, islandlike formation of alumina $(30 \mathrm{~nm})$ was observed as shown in Figure 1(b). This thin layer of alumina will act as the buffer layer for the growth of MWCNT by preventing silicidation of metal catalysts with Si surface during the growth process $[16,17]$. Without the buffer layer, the formation of Fe-Si can poison the catalyst and render it inactive for nanotubes formation. Iron was chosen as the metal catalyst for MWCNT growth since it has much higher crystallinity compared to nickel and cobalt [18]. Close inspection of the FESEM image in Figure 1(c) reveals a very thin layer of iron film after the deposition using electron beam evaporation. The EDX analysis as shown in the inset of Figure 1(c) also indicates a much weaker peak for iron deposited using electron beam evaporation as compared to ferrocene vaporization. The presence of hundreds of nanometer sparsely spread islands is believed to be the peeling of the film as a result of the cutting for cross-section sample preparation. Figure $1(\mathrm{~d})$ clearly describes a much thicker continuous film deposited using ferrocene vaporization (supported by EDX analysis) with typical minimal thickness of about $55 \mathrm{~nm}$ and average thickness of $85 \pm 23 \mathrm{~nm}$. As seen in Figure 2(d), the particle size is also much bigger and rougher compared to the one deposited by electron beam evaporation.

FESEM images in Figure 2 show the difference between the surface morphology of the iron film after the deposition using electron beam evaporation and ferrocene vaporization and subsequent surface treatment of annealing and etching. For both samples, particles agglomerated during the annealing process, forming larger particles as evident in Figures 2(b) and 2(e), but the size of particles for the film deposited by ferrocene vaporization is much larger: typically $900 \mathrm{~nm}$. Cracks can be seen (black arrows) in Figure 2(d) and become more pronounced in Figure 2(e). This is attributed to the fragmentation of a thick layer of iron as a result of surface stress. Annealing is usually performed to provide a strong bonding between catalyst and substrate.

During the growth, iron catalyst is partially oxidized as a result of the reaction with oxygen from alumina. The oxide can then prevent the formation of silicide that will deactivate the catalyst and promote nucleation of particles that acts as the growth seed $[19,20]$. Figures 2(c) and 2(f) show the surface morphology after etching using ammonia 


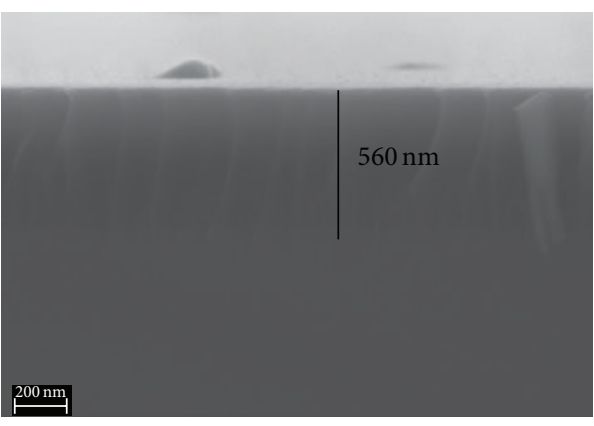

(a)

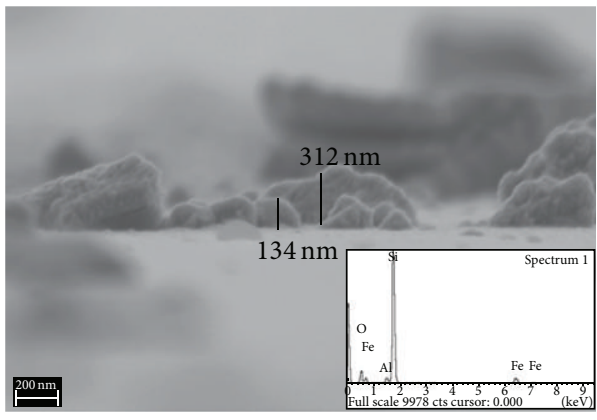

(c)

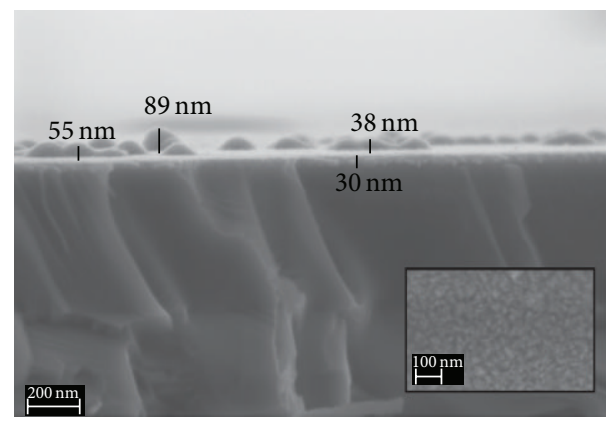

(b)

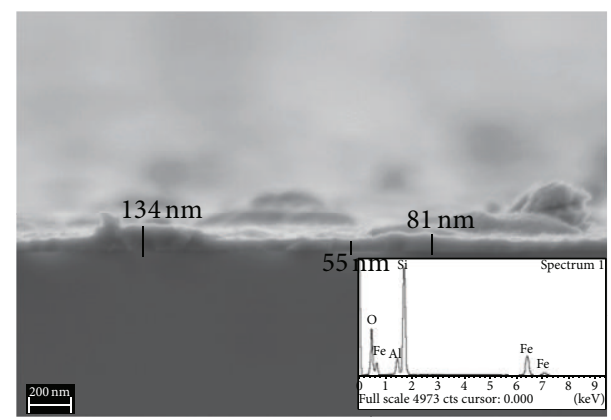

(d)

Figure 1: FESEM images of (a) thermally grown $\mathrm{SiO}_{2}$, (b) alumina thickness (inset: top view of alumina), (c) iron deposited using electron beam evaporation (inset: EDX analysis), and (d) iron deposited using ferrocene vaporization (inset: EDX analysis).

gas. Ammonia etching as argued by Choi et al. [21] and Teo et al. [22] and is crucial in forming nanoislands from continuous film of catalyst to promote aligned array of MWCNT. FESEM image reveals the formation of nanoislands after etching for both samples but with sample deposited by ferrocene vaporization (Figure 2(f)); micrometer size cavities are observed. There are also traces of nanoparticles inside the cavities. This is due to much thicker layer of iron $(\sim 55 \mathrm{~nm})$ deposited and, after etching, cavities are formed instead of nanoislands on the surface of the film.

The pretreated samples, ones that were subjected to annealing and etching, were then used for MWCNT growth. Grown MWCNT for treated and nontreated samples are compared by observing the FESEM images shown in Figure 3. The synthesis of MWCNT was performed for 20 minutes with hydrogen and ethylene as carbon feedstock. Figures 3(a), 3(b), and 3(c) are FESEM images of MWCNT grown on sample with electron beam coated iron film and Figures 3(d), 3(e), and 3(f) are FESEM images of MWCNT grown on sample with iron catalyst deposited by ferrocene vaporization. Aligned array of MWCNT was obtained only for samples deposited with iron by ferrocene vaporization. Figures 3(a) and $3(\mathrm{~d})$ are pretreated samples with annealing and etching. There are traces of nanotubes but overall the sample was covered with amorphous carbon or graphite as observed in Figure 3(a). Aligned MWCNT shown in Figure 3(d) is covered with amorphous carbon at the top surface and the alignment is not as good as the samples with combination of $\mathrm{Al}-\mathrm{Fe}$ and $\mathrm{Al}_{2} \mathrm{O}_{3}-\mathrm{Fe}$ which have not been subjected to the pretreatment. The role of catalyst is very important and the thickness of catalyst may determine the alignment of MWCNT array. For a very thin layer of catalyst, nanotubes can still grow but the low density of catalyst will lead to sparse growth of nanotubes with insufficient van der Waals forces between them such that they collapsed. Subsequently, the decomposed carbon will deposit as amorphous carbon or graphite. Study shows [23] that MWCNT self-organized due to the crowding effect at the start of the growth to form aligned MWCNT array when the catalyst density is high. The $\mathrm{Al}_{2} \mathrm{O}_{3}$ - $\mathrm{Fe}$ combination achieved good growth of MWCNT with minimal amorphous carbon and other by products on top of MWCNT array. During the ramping of temperature to $700^{\circ} \mathrm{C}$ in $\mathrm{Ar}$ ambient, the catalyst will be in molten form and interacts with the alumina and transforms into $\mathrm{Fe}_{2} \mathrm{O}_{3}$ particles. The thick film of catalyst with partial oxidation of iron promotes a good growth of vertically aligned MWCNT array since catalyst in oxide form has positive influence on MWCNT growth. As reported by Sato et al. [15] the heating of iron catalyst in air can produce iron oxide that can prevent silicidation which in turn can deactivate the catalyst. During the growth of MWCNT, the partially oxidized catalyst is reduced to metallic iron [24] which does not agglomerate thus maintaining the catalytic activity during the synthesis. The $\mathrm{H}_{2}$ treatment for 4 minutes will reduce and crack the catalyst film into fine particles since iron is active in metallic state. The above findings clearly show that the thickness of catalyst film can influence the alignment of MWCNT.

For comparison and to understand better the role of annealing, etching, and buffer layer, $\mathrm{Al}-\mathrm{Fe}$ and $\mathrm{Al}_{2} \mathrm{O}_{3}$-Fe films were deposited followed by MWCNT growth. FESEM images 


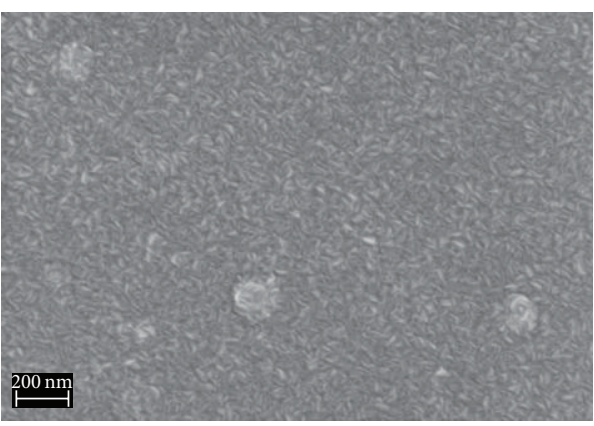

(a)

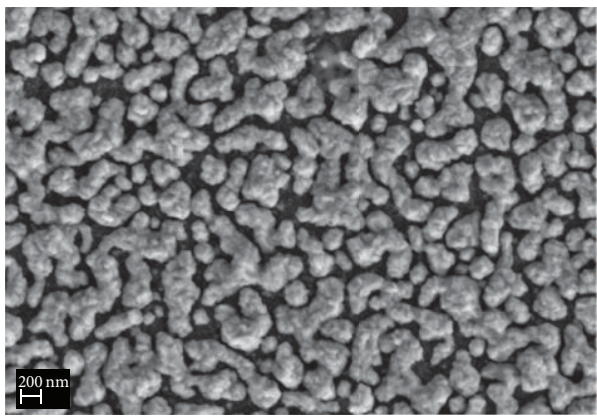

(c)

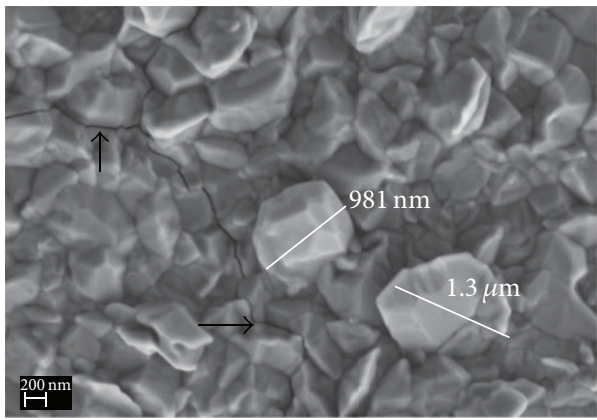

(e)

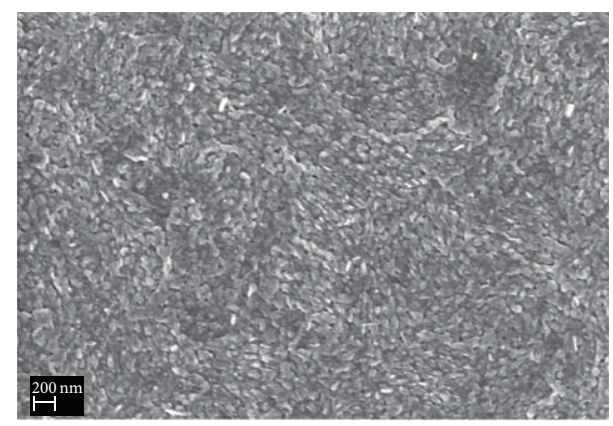

(b)

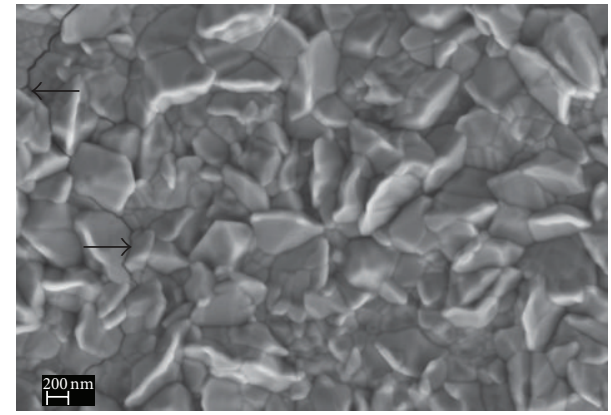

(d)

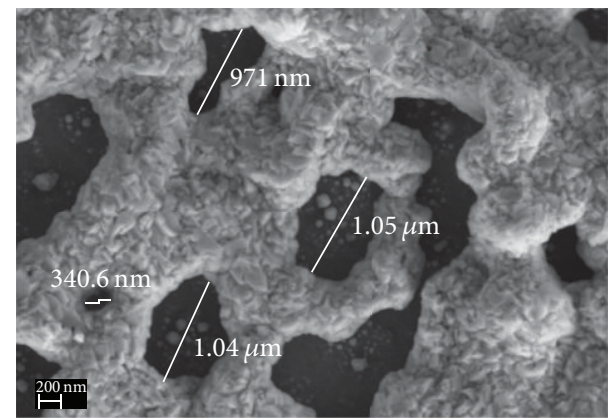

(f)

FIgURE 2: FESEM image of iron film (a) deposited by electron beam evaporation followed by (b) annealing and (c) etching process. FESEM image of iron film (d) deposited by ferrocene vaporization followed by (e) annealing and (f) etching process.

of graphite covered with nanotubes obtained are shown in Figures 3(b) and 3(c). de los Arcos et al. [25] reported no growth of nanotubes using pure $\mathrm{Al}$ as the buffer layer, contradicting earlier work by Delzeit et al. [26] where they reported growth of single-wall carbon nanotubes (SWCNT). The growth of nanotubes in Delzeit's work can be explained by the oxidation of iron film from oxygen in air during the transfer of the samples. In Teresa's work, the in situ observation was performed where iron was depleted due to the formation of Al-Si alloy.

This work reported a well-aligned MWCNT array using only $\mathrm{Al}$ as the buffer layer and iron catalyst deposited by ferrocene vaporization. This is a new finding since AlFe combination will poison and deactivate the catalyst, resulting in no growth of MWCNT. It is suspected that the Al buffer layer had oxidized in air during the transfer. In this case, the production of vertically well-aligned MWCNT observed in Figure 3(e) can be attributed to the crowding effect of the dense nanotubes grown from very thick layer of iron and the rough surface of catalyst (Figure 2(d)) that promotes the growth. The thickness of MWCNT array is also observed to be twice the height obtained for pretreated sample (Figure 3(d)) for the same synthesis reaction time.

Alumina buffer layer proved to be most suitable to avoid undesirable metal silicide formation at high temperature [27]. It is believed that, without the oxide, iron silicide will form, depleting iron catalyst for the formation of nanotubes. The absence of dense nanotubes for aluminum coated electron beam iron deposited sample can be observed clearly in Figure 3(b) where the very thin layer of iron has been depleted from the surface due to the formation of Al-Si alloy at the interface of the two elements. However, some nanotubes can still be observed, shown in the inset of Figure 3 (b) due to the presence of oxide (oxidation during transfer in air) and silicide which have been found to also promote the growth of MWCNT [28]. In contrast, dense 


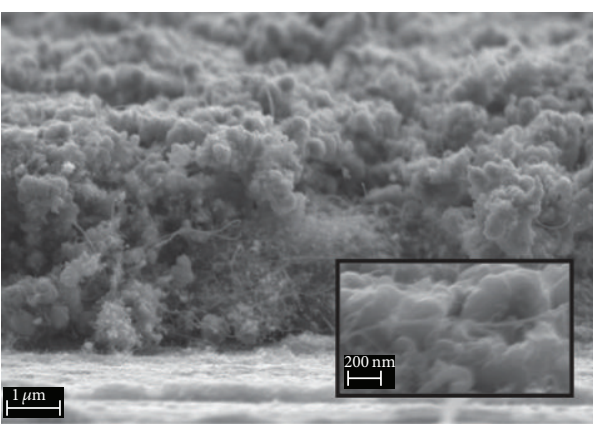

(a)

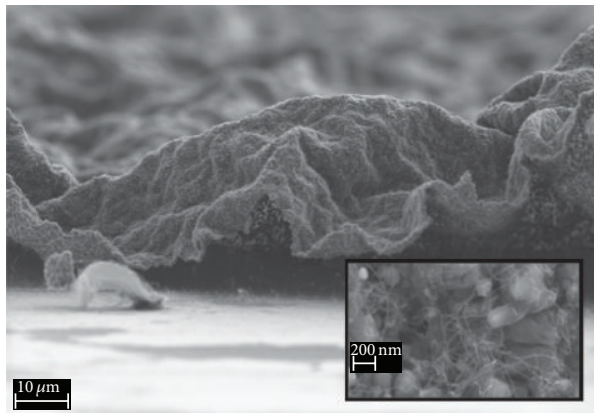

(c)

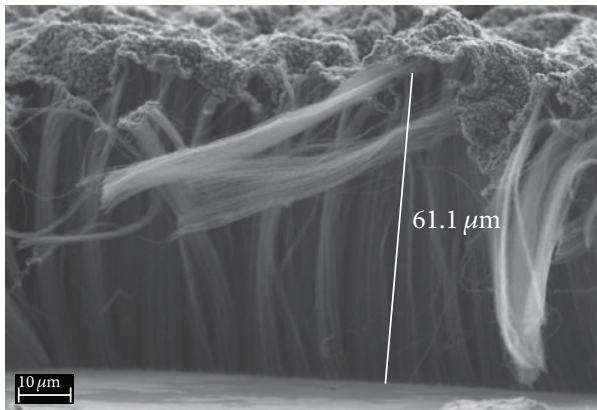

(e)

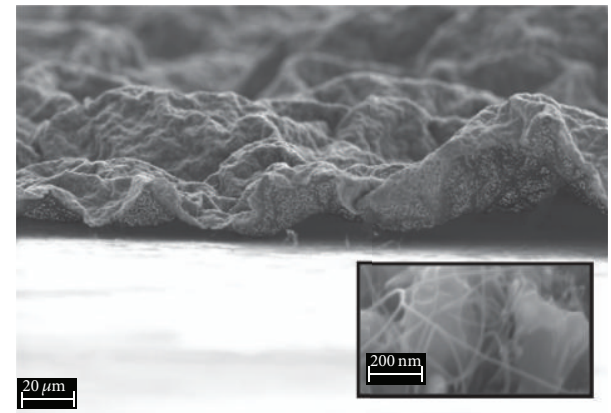

(b)

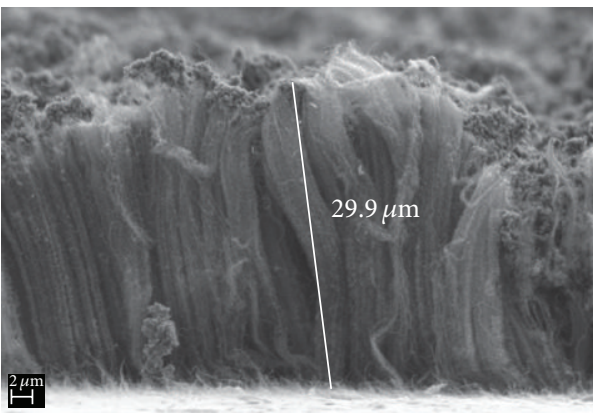

(d)

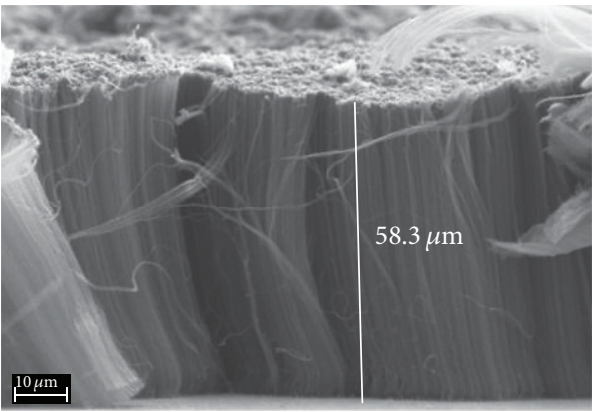

(f)

FIGURE 3: FESEM images of (a) MWCNT growth of pretreated sample (inset: presence of nanotubes), (b) MWCNT growth on Al-Fe (inset: presence of nanotubes), (c) MWCNT growth on $\mathrm{Al}_{2} \mathrm{O}_{3}-\mathrm{Fe}$ (inset: presence of nanotubes), (d) aligned array of MWCNT grown on pretreated sample, (e) aligned MWCNT growth on Al-Fe, and (f) aligned MWCNT growth on $\mathrm{Al}_{2} \mathrm{O}_{3}-\mathrm{Fe}$.

vertically aligned MWCNT (Figure 3(e)) can still be obtained for sample with iron deposited by ferrocene vaporization even without the oxide layer. It is suspected that even though poisoning of iron occurred at the interface of elements (Al-Si alloy with $\mathrm{Fe}$ ), the thick catalyst layer can provide sufficient active sites for the growth of vertically aligned nanotubes. The partial oxidation of the prepared substrates during the transfer in air also influences the growth of aligned MWCNT.

The adhesion between MWCNT film and the substrate was found to be weak such that the film peeled off easily as shown in Figure 4 for samples coated with iron by electron beam deposition and not treated with annealing. The peeling of MWCNT film was not observed for samples with iron deposited by ferrocene vaporization and not treated with annealing. It is believed that this is due to the thick layer of iron catalyst binding nanotubes to the substrate with the base growth mechanism.

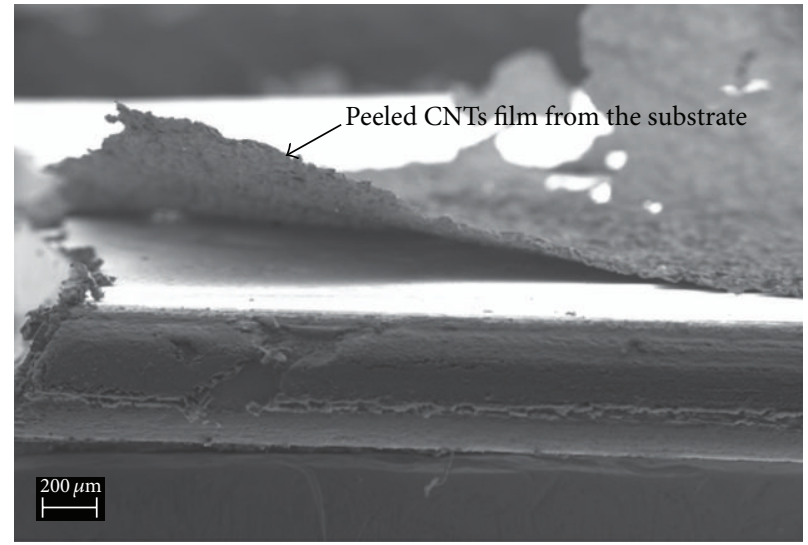

FIGURE 4: The graphite layer with traces of nanotubes peeled off from the substrate due to weak adhesion. 
The growth of random MWCNT observed for sample with iron deposited using electron beam evaporation is contradicting our previous work [14], where vertically aligned MWCNT array with thickness of $28 \mu \mathrm{m}$ was grown. It is understood that, for alignment of nanotubes, it needs high density of catalyst. As shown in Figures 1(c) and 2(a), the density of deposited iron using electron beam evaporation is low. This is believed to be due to the low pressure achieved in electron beam chamber $\left(2 \times 10^{-3}\right.$ Torr $)$ during iron deposition. The pressure should be at least $10^{-5}$ Torr to allow the passage of electrons from electron gun to the source to be evaporated [29]. The high vacuum also allows the ejected atoms from the source material to travel in a straight line to the substrate surface thus achieving a much thicker deposition. These processes however will not happen if the pressure is not low enough. As for the ferrocene vaporization, the vaporized iron is in gaseous form and it has an advantage of multidirectional deposition. This creates thicker and uniform iron distribution on the substrate surface as shown in Figure 1(d).

Raman spectrum shown in Figure 5 indicated the presence of MWCNT for all samples with the D-band occurring at $1371 \mathrm{~cm}^{-1}$ and G-band at $1607 \mathrm{~cm}^{-1}$ and no peak of radial breathing mode (RBM) for the presence of SWCNT. The Gband indicates the graphitic features of MWCNT and the Dband explains the disordered features mainly the disordered walls or graphite on the outer walls of nanotubes [30, 31].

The deposited metallic $\mathrm{Al}$ shows peaks at 72.98 and at $75.2 \mathrm{eV}$ in the XPS analysis in Figure 6(a), indicating the sample being partially oxidized when exposed to air during the transfer of sample for ex situ examination. After the oxidation process to form alumina, prominent peak occurs at $75.7 \mathrm{eV}(\mathrm{Al} 2 \mathrm{p})$, showing a fully oxidized state. There are no traces of $\mathrm{Al}$ after iron deposition and annealing, an indication that there is no interaction between $\mathrm{Al}$ and $\mathrm{Fe}$. After etching, a small $\mathrm{Al} 2 \mathrm{p}$ peak is observed at $75 \mathrm{eV}$ showing the distribution of iron into nanoisland particles as observed in Figure 2(c). The same Al transformation is observed for sample with iron deposited by ferrocene evaporation (Figure 6(b)) with only a slight difference for $\mathrm{Al}$ peak after etching of which the peak is on upper binding energy compared to $\mathrm{Al}$ peak for electron beam evaporation on lower binding energy. This $1.3 \mathrm{eV}$ shift may be an indication that iron is not fully depleted but, for sample with iron deposited by electron beam evaporation, the iron thickness becomes much thinner and sparse leading to random growth of MWCNT instead of aligned MWCNT array.

In Figure 7, iron shows partially oxidized peak at $710.88 \mathrm{eV}$ for electron beam evaporation technique and $711.78 \mathrm{eV}$ with slight variation after annealing $(711.38 \mathrm{eV})$ and etching $(710.68 \mathrm{eV})$ for ferrocene vaporization in which the oxidation occurs during the exposure to air. These peaks are characteristic of magnetite, indicating coexistence of $\mathrm{FeO}$ and $\mathrm{Fe}_{2} \mathrm{O}_{3}$. The ferrocene will decompose into metal iron, hydrogen, and hydrocarbons during vaporization according to the reaction shown in the following [32]:

$$
\mathrm{Fe}\left(\mathrm{C}_{5} \mathrm{H}_{5}\right)_{2} \longrightarrow \mathrm{Fe}+\mathrm{H}_{2}+\mathrm{CH}_{4}+\mathrm{C}_{5} \mathrm{H}_{6}+\cdots
$$

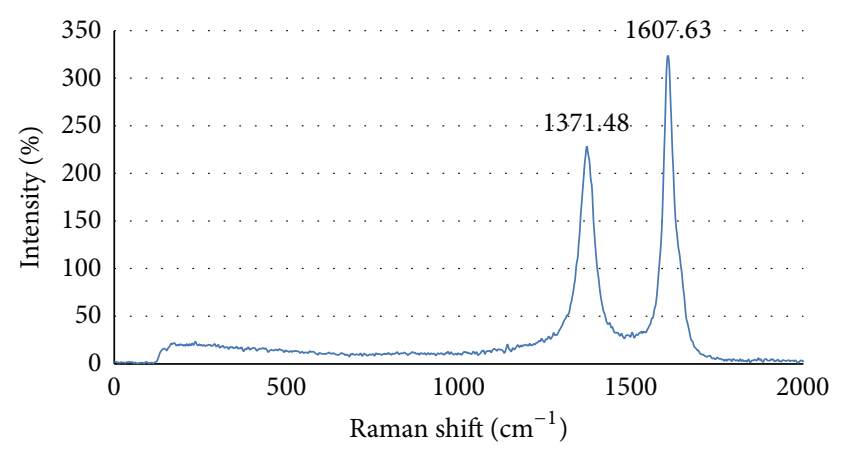

FIgURE 5: Typical Raman spectrum for MWCNT.

The iron catalyst will be oxidized during this process after its release from ferrocene. Then the peak intensity reduced about $24 \%$, attributed to the distribution of iron and some loss by diffusion. The peak intensity further reduced by $33 \%$ for electron beam evaporation method indicating island-like formation after etching as observed in Figure 2(c). There are no traces of $\mathrm{Si} 2 \mathrm{p}$ (not shown here) after every process (iron deposition, annealing, and etching), indicating that $\mathrm{Al}$ Si interdiffusion does not occur due to the presence of oxide layer. As for the iron deposited using ferrocene vaporization (Figure 7(b)), the intensity and the peak are the same, a further proof that thick layer of iron does not contribute to the dispersion of iron. However, after etching, the intensity of the peak reduced due to the etching of iron from the surface to form cavities as shown in Figure 2(f).

We concluded that the thickness of iron catalyst is important in achieving well-aligned MWCNT growth. We have reported elsewhere [33] the growth of MWCNT using floating catalyst CVD technique but the growth rate was found to be difficult to control. Based on the SEM, Raman, and XPS analysis, thermal CVD technique with iron deposited by ferrocene vaporization will be chosen since a thick layer of catalyst $(>55 \mathrm{~nm})$ can be achieved producing dense, vertically aligned MWCNT. With this method, good growth rate can be achieved initially but after a prolonged period of time the growth rate dropped slightly.

Figure 8 shows the SEM images of MWCNT array grown for $9,10,11$, and 12 minutes where the growth rate remained steady. As shown in Figure 9, a steady growth rate of $3.6 \mu \mathrm{m} / \mathrm{min}$ was recorded for the first 12 minutes but beyond that dropped to $3.1 \mu \mathrm{m} / \mathrm{min}$ and further reduced to nearly half of the initial growth rate. The drop in the growth rate is illustrated by the thickness of MWCNT array obtained for the durations of 20,40, and 60 minutes in Figure 10. The thickness of MWCNT array should be higher if the growth rate remained steady for these periods. Reduced growth rate with the duration of the synthesis is believed to be due to the coating of amorphous carbon or graphite on top of the MWCNT mat. Hydrogen is included during the synthesis since it can etch away amorphous carbon deposit on the catalyst and block the nanotubes growth [34]. But its function is significantly reduced once the MWCNT array has formed. The decomposed carbon cannot reach the catalyst due to dense and crowded nanotubes mat and these carbons will 


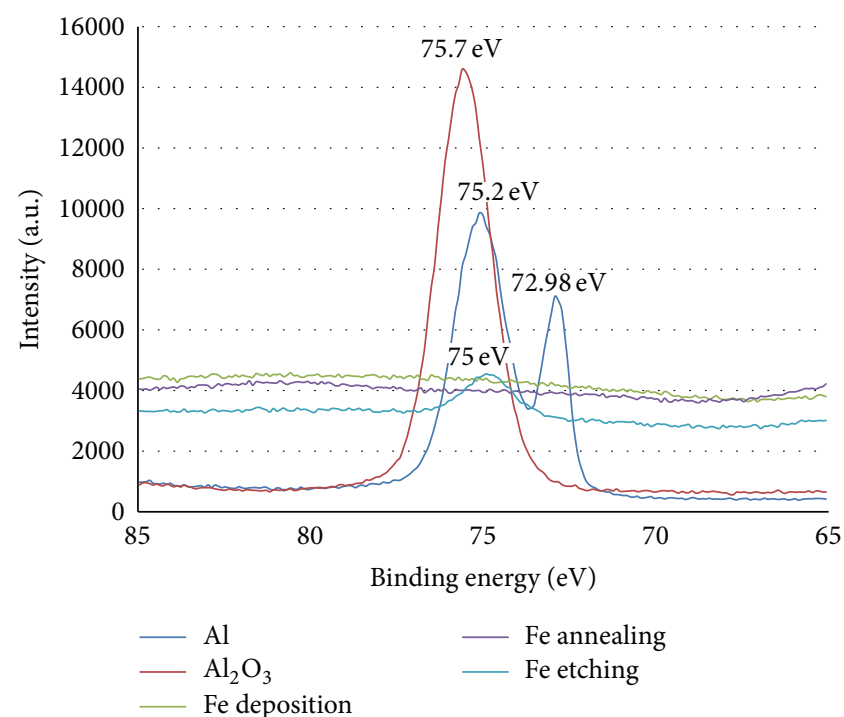

(a)

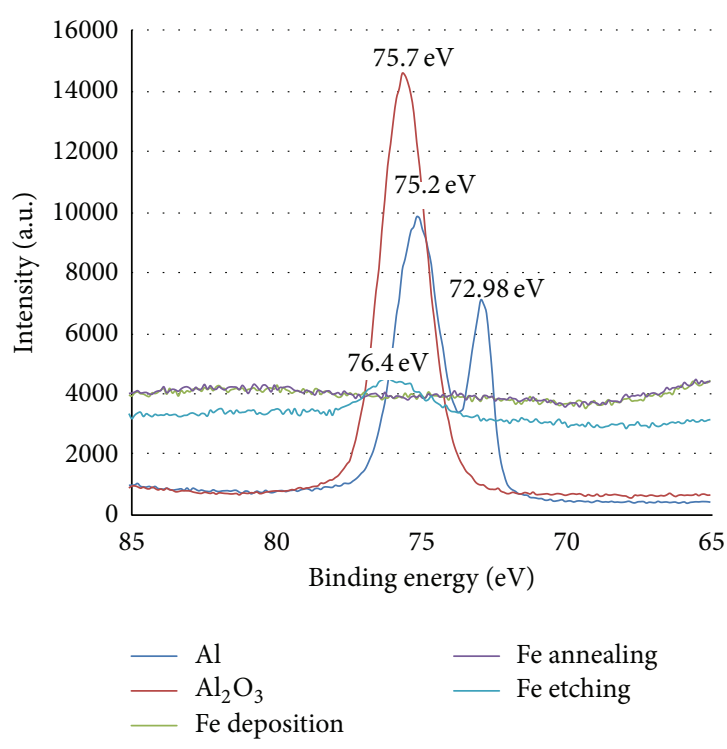

(b)

FIGURE 6: XPS analysis of Al peaks for sample with iron catalyst deposited by (a) electron beam evaporation and (b) ferrocene vaporization.

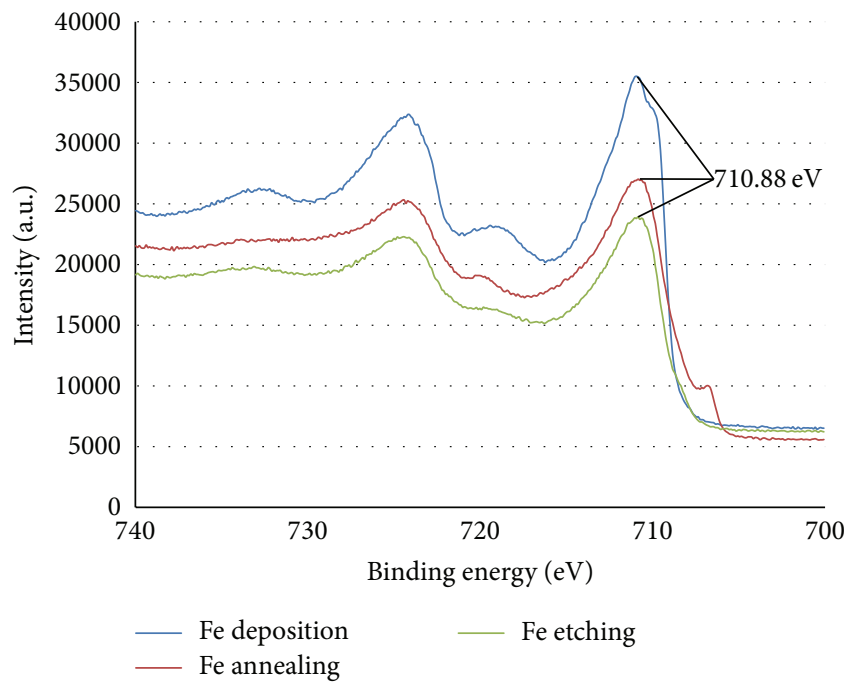

(a)

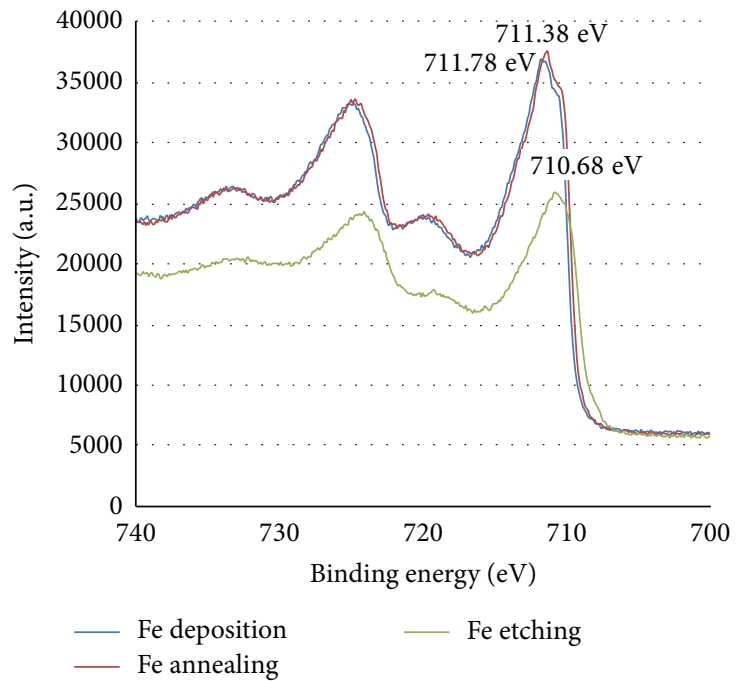

(b)

FIGURE 7: XPS analysis of Fe peaks for sample with iron catalyst deposited by (a) electron beam evaporation and (b) ferrocene vaporization.

be deposited on the top of the MWCNT surface as shown clearly in Figure 10. When the synthesis of MWCNT had stopped, the residue of the remaining decomposed carbon will deposit on top of the surface, acting as a passivation layer that hinders the growth of nanotubes. This explains the trend of the growth rate which is uniform in the beginning and reduces linearly over a period of time.

The growth rate or the corresponding MWCNT thickness matches well the thickness reported by Bronikowski [35] for the early stage growth. It also shows an exponential decay as the duration of synthesis is prolonged due to reduced activity of catalyst from the coating of amorphous carbon. The experimental data was fitted with mathematical model developed by Naha and Puri [36] and, as observed in Figure 9, it has marked deviation although it fitted well in its initial stage ( $<15 \mathrm{~min})$. The difference is mainly due to the constants calculated for adsorption and desorption of the carbon atoms at the surface of catalyst, nucleation, and separation of solid undissolved carbon by them. Both calculated and experimental data agreed that the growth rate of nanotubes reduced exponentially as the synthesis time is prolonged. Einarsson et al. [37] also shows an optimum growth time of $15 \mathrm{~min}$ and exponential decay after the initial maximum growth rate.

Various mathematical models [36-39] and simulations [40-42] were developed in attempt to understand the nature 


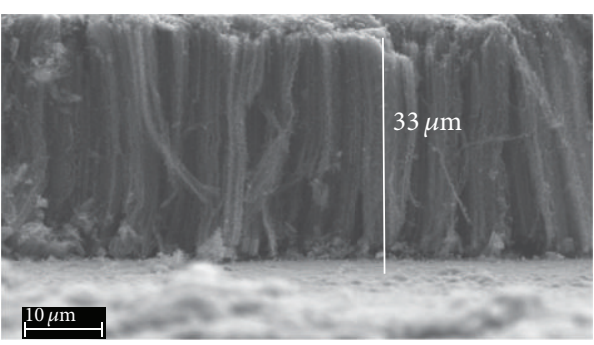

(a)

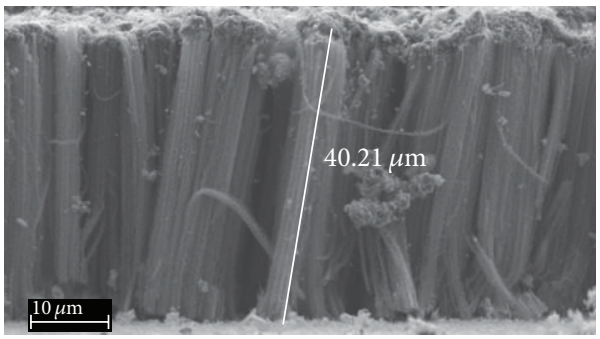

(c)

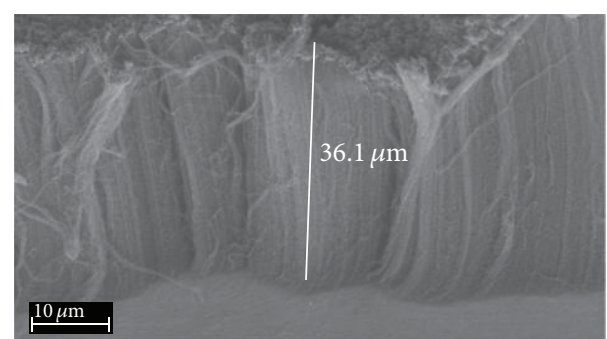

(b)

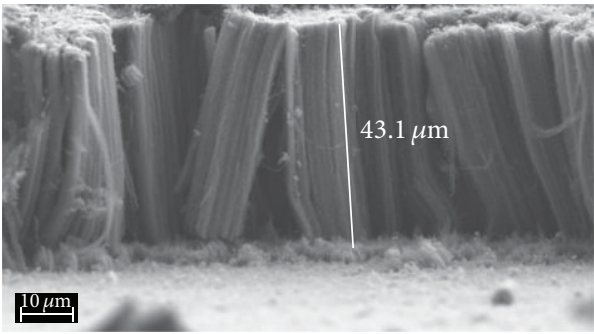

(d)

FIGURE 8: Aligned array of MWCNT grown for (a) 9, (b) 10, (c) 11, and (d) 12 minutes.

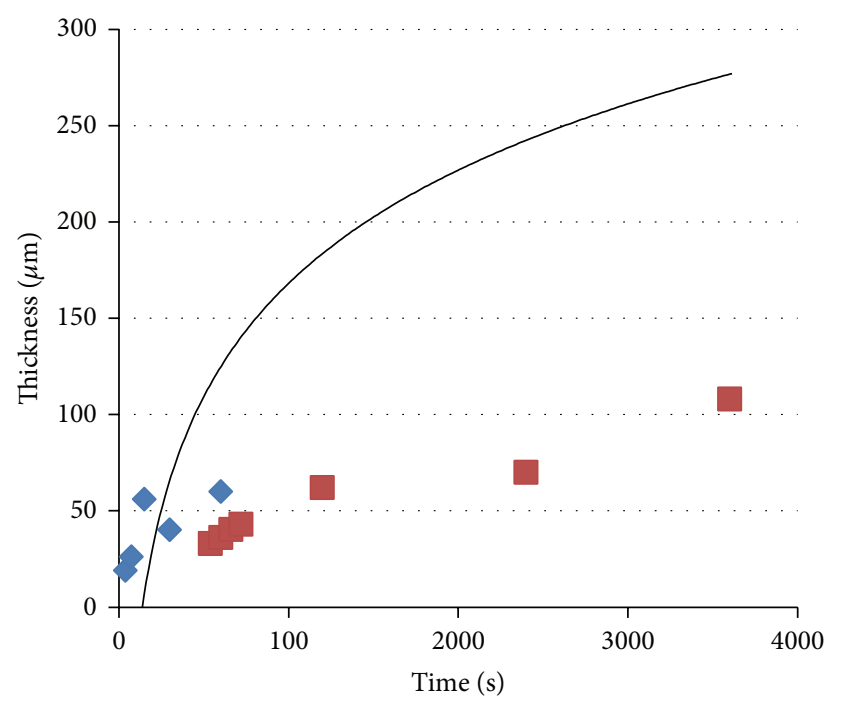

- Experimental data from Bronikowski (2006)

- Experimental data from this work

— Log. (mathematical model by Naha and Puri (2008))

FIGURE 9: MWCNT thickness obtained using thermal CVD method.

of nanotubes growth rate. The growth rate of nanotubes depends on growth kinetics, activation energy, and transport resistances. Latorre et al. [39] developed a phenomenological kinetic model that includes the relevant parameters such as carbon source decomposition, nanoparticles surface carburization, carbon diffusion, nucleation, nanotubes growth, and growth termination which usually occur due to catalyst deactivation and steric hindrance. Gas concentration, pressure, temperature, and flow rate of carbon source also can affect the growth rate of MWCNT. Water vapor had been introduced
[42] to overcome this problem since it acts as weak oxidizer to etch the deposited amorphous carbon and maintain the growth rate.

The properties of the grown nanotubes such as type, resistivity, and electron mobility were obtained using Ecopia Hall Effect measurement. The grown MWCNT shown in Figure 8 are of p-type with resistivity ranging from 1.54 to $2.17 \times$ $10^{-7} \Omega \mathrm{m}$ and electron mobility of $3.16-6.72 \mathrm{~m}^{2} / \mathrm{Vs}$. High aspect ratio MWCNT in the range of 2400-7800 reported here is suitable for applications such as field emission display, pressure, and gas sensors. The control of growth rate will be critical if specific thickness of MWCNT array is required for certain application such as ionization-based gas sensor using nanotubes array as the sensing element.

Figure 11 shows a typical TEM image of thinner nanotubes obtained using alumina as the buffer layer. This particular observation agrees well with de los Arcos et al. [20], implying that alumina promotes the growth of thinner nanotubes compared to other buffer layers such TiN and $\mathrm{TiO}_{2}$. The nanotube has a diameter of $27.5 \mathrm{~nm}$ with more than 16 walls. Discontinuity and graphitic coating on the outer wall of nanotubes can also be observed. These are the main reason why MWCNT has lower crystallinity or are more defective than SWCNT.

\section{Conclusion}

The thickness of catalyst layer, presence of oxide, and type of buffer layer are all equally important for the growth and alignment of MWCNT. The presence of oxide avoids the agglomeration of Fe catalyst thus promoting the formation of MWCNT. The introduction of buffer layer avoids silicidation and provides support for the growth of MWCNT. The buffer layer especially $\mathrm{Al}_{2} \mathrm{O}_{3}$ is also known to increase the growth 


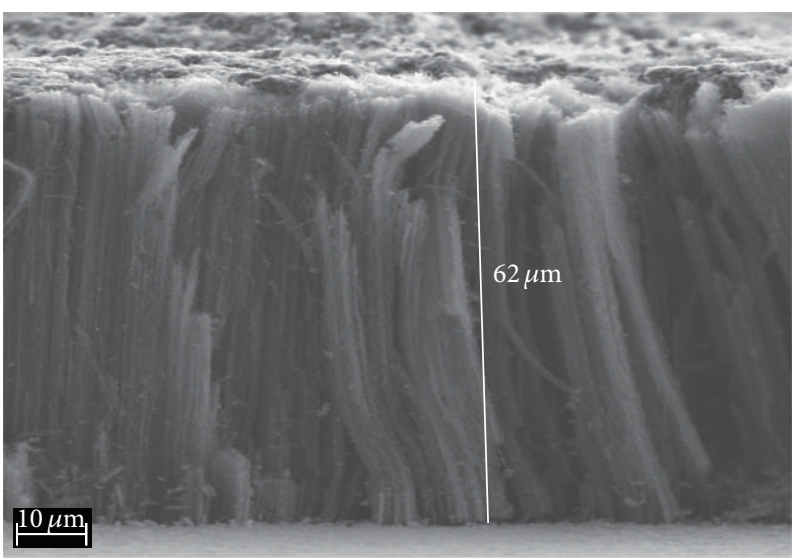

(a)

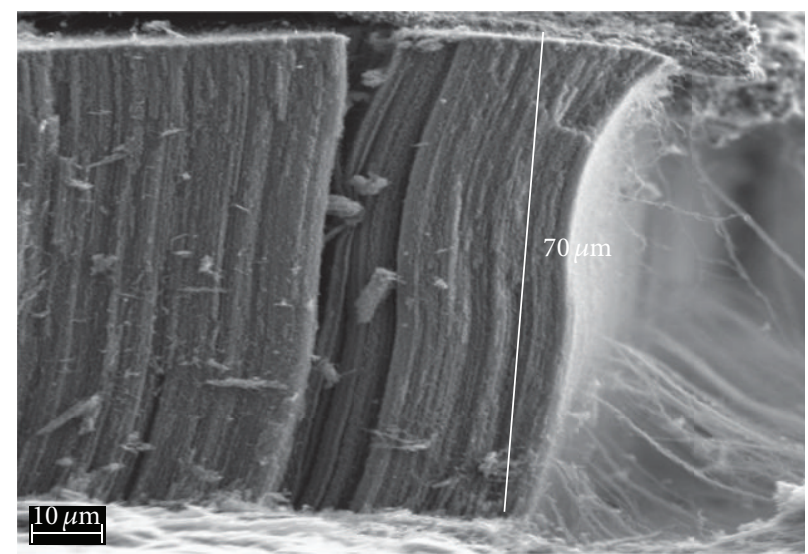

(b)

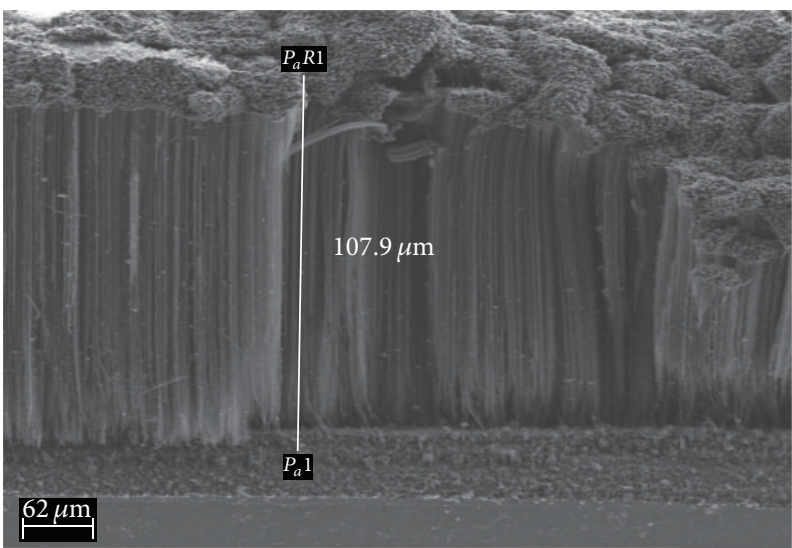

(c)

FIGURE 10: FESEM images of MWCNT grown for (a) 20, (b) 40, and (c) 60 minutes.

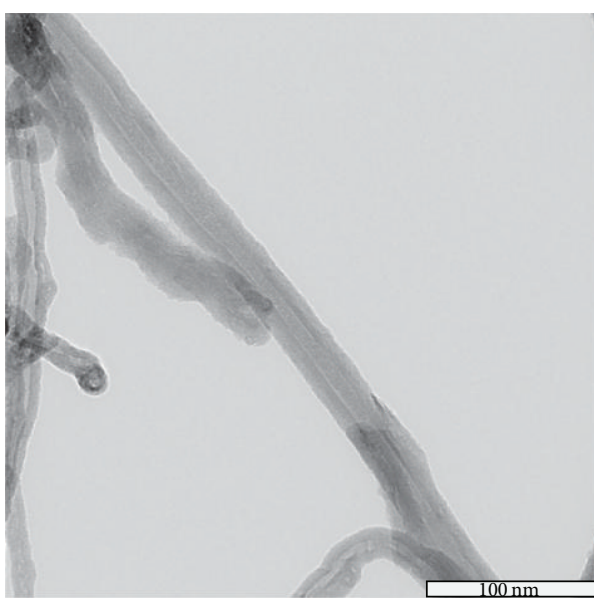

(a)

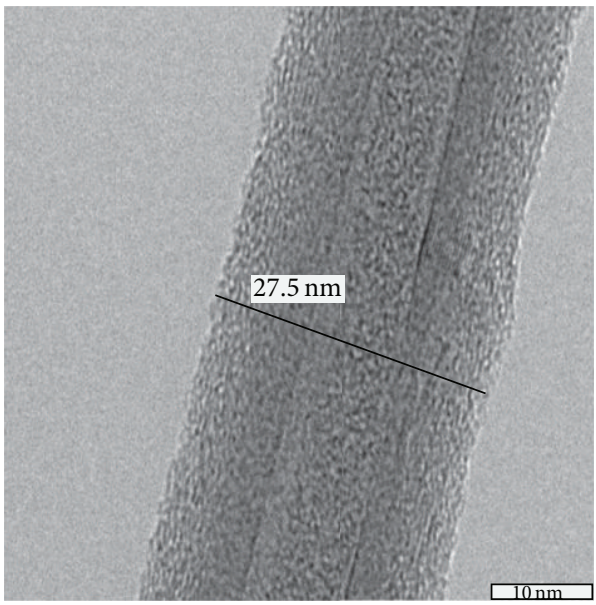

(b)

FIGURE 11: TEM image of (a) nanotubes grown from the sample with (b) a close-up view of a typical nanotube.

rate of MWCNT. The $\mathrm{Al}_{2} \mathrm{O}_{3}$ and $\mathrm{Fe}$ film has proven to be the best combination since, at $700^{\circ} \mathrm{C}$ in argon ambient, iron partially oxidized due to diffusion with $\mathrm{Al}_{2} \mathrm{O}_{3}$ and remained on the surface for an efficient growth of MWCNT.

Vertically aligned MWCNT array has been successfully grown with $\mathrm{Al}_{2} \mathrm{O}_{3}$ as the buffer layer using the deposition of iron catalyst by ferrocene vaporization. In this method, the growth rate of MWCNT array remained steady at $3.6 \mu \mathrm{m} / \mathrm{min}$ in the first 12 minutes but dropped by half for the longer period. For electron beam deposited iron catalyst, high vacuum preferably $10^{-5}$ Torr is required for optimum catalyst density to grow aligned MWCNT as demonstrated in 
the previous work. On the other hand, pressure does not play any role in the ferrocene vaporization. The gaseous form and multidirectional deposition of ferrocene vaporization gives a uniform and high density catalyst layer required for the growth of aligned MWCNT.

Understanding the effect of the metal catalyst deposition method on the density, thickness and alignment of the nanotubes array grown would allow for the optimization of the process in order to produce good quality, vertically aligned nanotubes that can exhibit enhanced functionality for the development of high performing nanotubes-based devices.

\section{Conflict of Interests}

The authors declare that there is no conflict of interests regarding the publication of this paper.

\section{Acknowledgments}

The authors wish to express their gratitude to Universiti Teknologi PETRONAS for the financial support of the research work.

\section{References}

[1] M. Kumar and Y. Ando, "Chemical vapor deposition of carbon nanotubes: a review on growth mechanism and mass production," Journal of Nanoscience and Nanotechnology, vol. 10, no. 6, pp. 3739-3758, 2010.

[2] K. Hata, D. N. Futaba, K. Mizuno, T. Namai, M. Yumura, and S. Iijima, "Water-assisted highly efficient synthesis of impurityfree single-walled carbon nanotubes," Science, vol. 306, no. 5700, pp. 1362-1364, 2004.

[3] M. Kumar and Y. Ando, "A simple method of producing aligned carbon nanotubes from an unconventional precursor-Camphor," Chemical Physics Letters, vol. 374, no. 5-6, pp. 521-526, 2003.

[4] B. Kitiyanan, W. E. Alvarez, J. H. Harwell, and D. E. Resasco, "Controlled production of single-wall carbon nanotubes by catalytic decomposition of CO on bimetallic Co-Mo catalysts," Chemical Physics Letters, vol. 317, no. 3-5, pp. 497-503, 2000.

[5] C. L. Cheung, A. Kurtz, H. Park, and C. M. Lieber, "Diametercontrolled synthesis of carbon nanotubes," Journal of Physical Chemistry B, vol. 106, no. 10, pp. 2429-2433, 2002.

[6] F. Ding, P. Larsson, J. A. Larsson et al., "The importance of strong carbon-metal adhesion for catalytic nucleation of singlewalled carbon nanotubes," Nano Letters, vol. 8, no. 2, pp. 463468, 2008.

[7] S. Fan, M. G. Chapline, N. R. Franklin, T. W. Tombler, A. M. Cassell, and H. Dai, "Self-oriented regular arrays of carbon nanotubes and their field emission properties," Science, vol. 283, no. 5401, pp. 512-514, 1999.

[8] A. M. Fennimore, T. D. Yuzvinsky, W.-Q. Han, M. S. Fuhrer, J. Cumings, and A. Zetti, "Rotational actuators based on carbon nanotubes," Nature, vol. 424, no. 6947, pp. 408-410, 2003.

[9] C. Liu, Y. Y. Fan, M. Liu, H. T. Cong, H. M. Cheng, and M. S. Dresselhaus, "Hydrogen storage in single-walled carbon nanotubes at room temperature," Science, vol. 286, no. 5442, pp. 1127-1129, 1999.
[10] A. Modi, N. Koratkar, E. Lass, B. Wei, and P. M. Ajayan, "Miniaturized gas ionization sensors using carbon nanotubes," Nature, vol. 424, no. 6945, pp. 171-174, 2003.

[11] D. Villers, S. H. Sun, A. M. Serventi, J. P. Dodelet, and S. Désilets, "Characterization of Pt nanoparticles deposited onto carbon nanotubes grown on carbon paper and evaluation of this electrode for the reduction of oxygen," Journal of Physical Chemistry B, vol. 110, no. 51, pp. 25916-25925, 2006.

[12] Y. J. Jung, B. Wei, R. Vajtai et al., "Mechanism of selective growth of carbon nanotubes on $\mathrm{SiO}_{2} / \mathrm{Si}$ patterns," Nano Letters, vol. 3, no. 4, pp. 561-564, 2003.

[13] P. M. Parthangal, R. E. Cavicchi, and M. R. Zachariah, "A generic process of growing aligned carbon nanotube arrays on metals and metal alloys," Nanotechnology, vol. 18, no. 18, Article ID 185605, 2007.

[14] M. K. Lai, N. M. Mohamed, and K. M. Begam, "The role of $\mathrm{Al}_{2} \mathrm{O}_{3}$ buffer layer in the growth of aligned CNTs," Advanced Materials Research, vol. 32, pp. 29-32, 2008.

[15] H. Sato, Y. Hori, K. Hata, K. Seko, H. Nakahara, and Y. Saito, "Effect of catalyst oxidation on the growth of carbon nanotubes by thermal chemical vapor deposition," Journal of Applied Physics, vol. 100, no. 10, Article ID 104321, 2006.

[16] H. Liu, Y. Zhang, D. Arato, R. Li, P. Mérel, and X. Sun, "Aligned multi-walled carbon nanotubes on different substrates by floating catalyst chemical vapor deposition: critical effects of buffer layer," Surface and Coatings Technology, vol. 202, no. 17, pp. 4114-4120, 2008.

[17] Y. Yao, L. K. L. Falk, R. E. Morjan, O. A. Nerushev, and E. E. B. Campbell, "Nucleation and aligned growth of multi-wall carbon nanotube films during thermal CVD," Carbon, vol. 45, no. 10, pp. 2065-2071, 2007.

[18] C. J. Lee, J. Park, and J. A. Yu, "Catalyst effect on carbon nanotubes synthesized by thermal chemical vapor deposition," Chemical Physics Letters, vol. 360, no. 3-4, pp. 250-255, 2002.

[19] D. J. Yang, Q. Zhang, S. F. Yoon et al., "Effects of oxygen and nitrogen on carbon nanotube growth using a microwave plasma chemical vapor deposition technique," Surface and Coatings Technology, vol. 167, no. 2-3, pp. 288-291, 2003.

[20] T. de los Arcos, P. Oelhafen, and D. Mathys, "The importance of catalyst oxidation for the growth of carbon nanotubes on $\mathrm{Si}$ substrates," Carbon, vol. 47, no. 8, pp. 1977-1982, 2009.

[21] K. S. Choi, Y. S. Cho, S. Y. Hong, J. B. Park, D. J. Kim, and H. J. Kim, "The role of ammonia treatment in the alignment of the carbon nanotubes synthesized with $\mathrm{Ni}$ and Fe via thermal chemical vapor deposition," Journal of the Korean Physical Society, vol. 39, no. 1, pp. S7-S10, 2001.

[22] K. B. K. Teo, M. Chhowalla, G. A. J. Amaratunga et al., "Uniform patterned growth of carbon nanotubes without surface carbon," Applied Physics Letters, vol. 79, no. 10, pp. 1534-1536, 2001.

[23] R. Andrews, D. Jacques, A. M. Rao et al., "Continuous production of aligned carbon nanotubes: a step closer to commercial realization," Chemical Physics Letters, vol. 303, no. 5-6, pp. 467474, 1999.

[24] S. Hofmann, R. Blume, C. T. Wirth et al., "State of transition metal catalysts during carbon nanotube growth," Journal of Physical Chemistry C, vol. 113, no. 5, pp. 1648-1656, 2009.

[25] T. de los Arcos, M. G. Garnier, P. Oelhafen et al., "Strong influence of buffer layer type on carbon nanotube characteristics," Carbon, vol. 42, no. 1, pp. 187-190, 2004.

[26] L. Delzeit, I. McAninch, B. A. Cruden et al., "Growth of multiwall carbon nanotubes in an inductively coupled plasma 
reactor," Journal of Applied Physics, vol. 91, no. 9, pp. 6027-6033, 2002.

[27] T. de los Arcos, Z. M. Wu, and P. Oelhafen, "Is aluminum a suitable buffer layer for carbon nanotube growth?" Chemical Physics Letters, vol. 380, no. 3-4, pp. 419-423, 2003.

[28] A. Hähnel and J. Woltersdorf, "Structuring of carbon layers in Si-C-O systems studied on atomic scale," Thin Solid Films, vol. 482, no. 1-2, pp. 19-23, 2005.

[29] K. S. S. Harsha, Principles of Vapor Deposition of Thin Films, Elsevier, London, UK, 2006.

[30] M. S. Dresselhaus, G. Dresselhaus, R. Saito, and A. Jorio, "Raman spectroscopy of carbon nanotubes," Physics Reports, vol. 409, no. 2, pp. 47-99, 2005.

[31] M. Zdrojek, W. Gebicki, C. Jastrzebski, T. Melin, and A. Huczko, "Studies of multiwall carbon nanotubes using raman spectroscopy and atomic force microscopy," Diffusion and Defect Data B: Solid State Phenomena, vol. 99-100, pp. 265-268, 2004.

[32] A. Leonhardt, S. Hampel, C. Müller et al., "Synthesis, properties, and applications of ferromagnetic-filled carbon nanotubes," Chemical Vapor Deposition, vol. 12, no. 6, pp. 380-387, 2006.

[33] M. S. M. Saheed, N. M. Mohamed, and Z. A. Burhanudin, "Optimization of the production of aligned CNTs array as the gas sensing element," Materials Science Forum, vol. 756, pp. 156-163, 2013.

[34] M. J. Behr, E. A. Gaulding, K. A. Mkhoyan, and E. S. Aydil, "Effect of hydrogen on catalyst nanoparticles in carbon nanotube growth," Journal of Applied Physics, vol. 108, no. 5, Article ID 053303, 2010.

[35] M. J. Bronikowski, "CVD growth of carbon nanotube bundle arrays," Carbon, vol. 44, no. 13, pp. 2822-2832, 2006.

[36] S. Naha and I. K. Puri, "A model for catalytic growth of carbon nanotubes," Journal of Physics D, vol. 41, no. 6, Article ID 065304, 2008.

[37] E. Einarsson, Y. Murakami, M. Kadowaki, and S. Maruyama, "Growth dynamics of vertically aligned single-walled carbon nanotubes from in situ measurements," Carbon, vol. 46, no. 6, pp. 923-930, 2008.

[38] X. Feng, K. Liu, X. Xie et al., "Thermal analysis study of the growth kinetics of carbon nanotubes and epitaxial graphene layers on them," Journal of Physical Chemistry C, vol. 113, no. 22, pp. 9623-9631, 2009.

[39] N. Latorre, E. Romeo, F. Cazaña et al., "Carbon nanotube growth by catalytic chemical vapor deposition: a phenomenological kinetic model," Journal of Physical Chemistry C, vol. 114, no. 11, pp. 4773-4782, 2010.

[40] J.-Y. Raty, F. Gygi, and G. Galli, "Growth of carbon nanotubes on metal nanoparticles: a microscopic mechanism from $a b$ initio molecular dynamics simulations," Physical Review Letters, vol. 95, no. 9, Article ID 096103, 2005.

[41] A. J. Page, H. Yamane, Y. Ohta, S. Irle, and K. Morokuma, "QM/ MD simulation of SWNT nucleation on transition-metal carbide nanoparticles," Journal of the American Chemical Society, vol. 132, no. 44, pp. 15699-15707, 2010.

[42] M. Lubej and I. Plazl, “Theoretical descriptions of carbon nanotubes synthesis in a chemical vapor deposition reactor: a review," Chemical and Biochemical Engineering Quarterly, vol. 26, no. 3, pp. 277-284, 2012. 

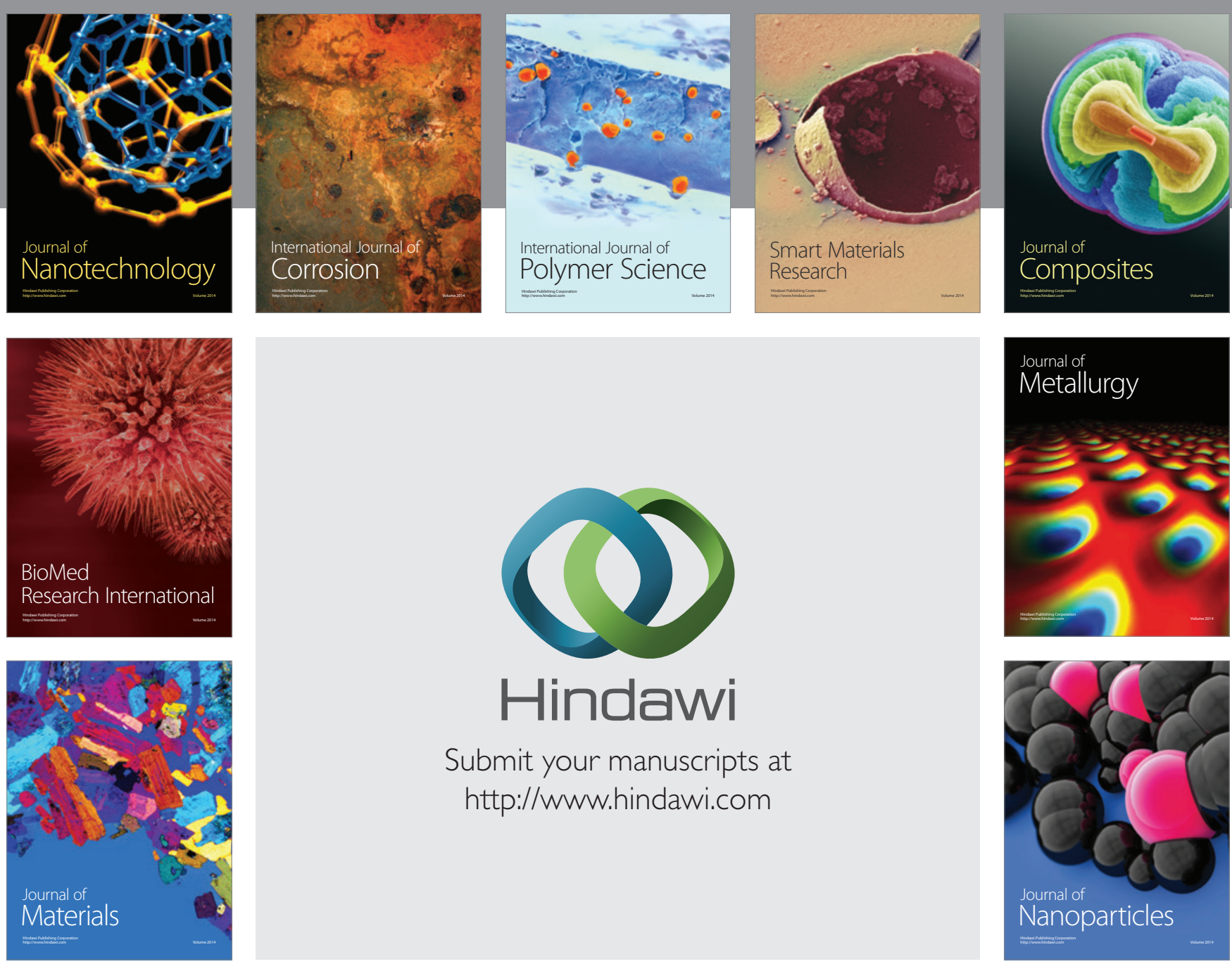

Submit your manuscripts at http://www.hindawi.com
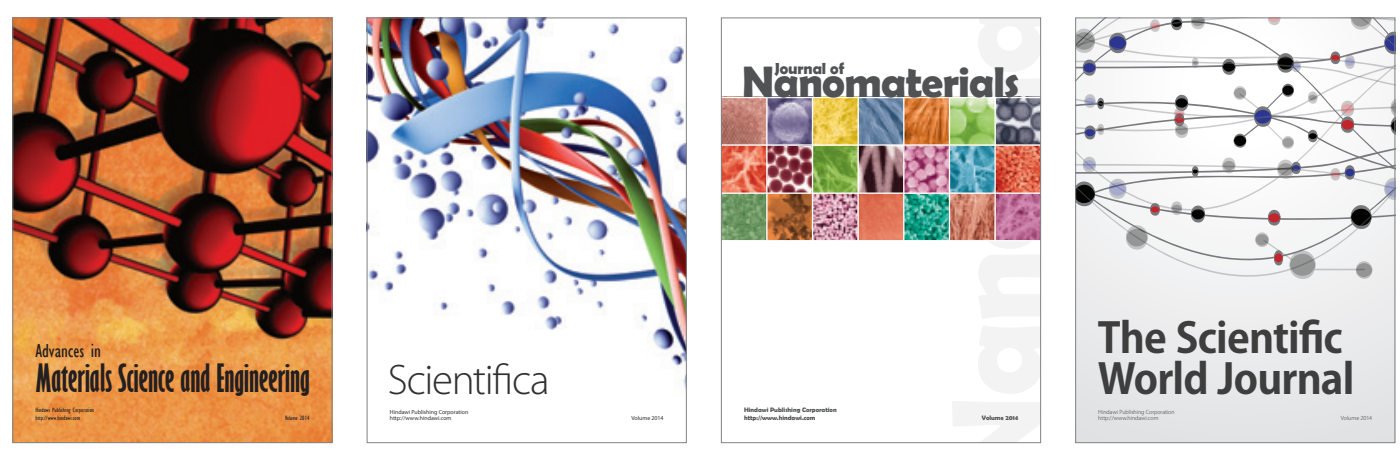

\section{The Scientific World Journal}
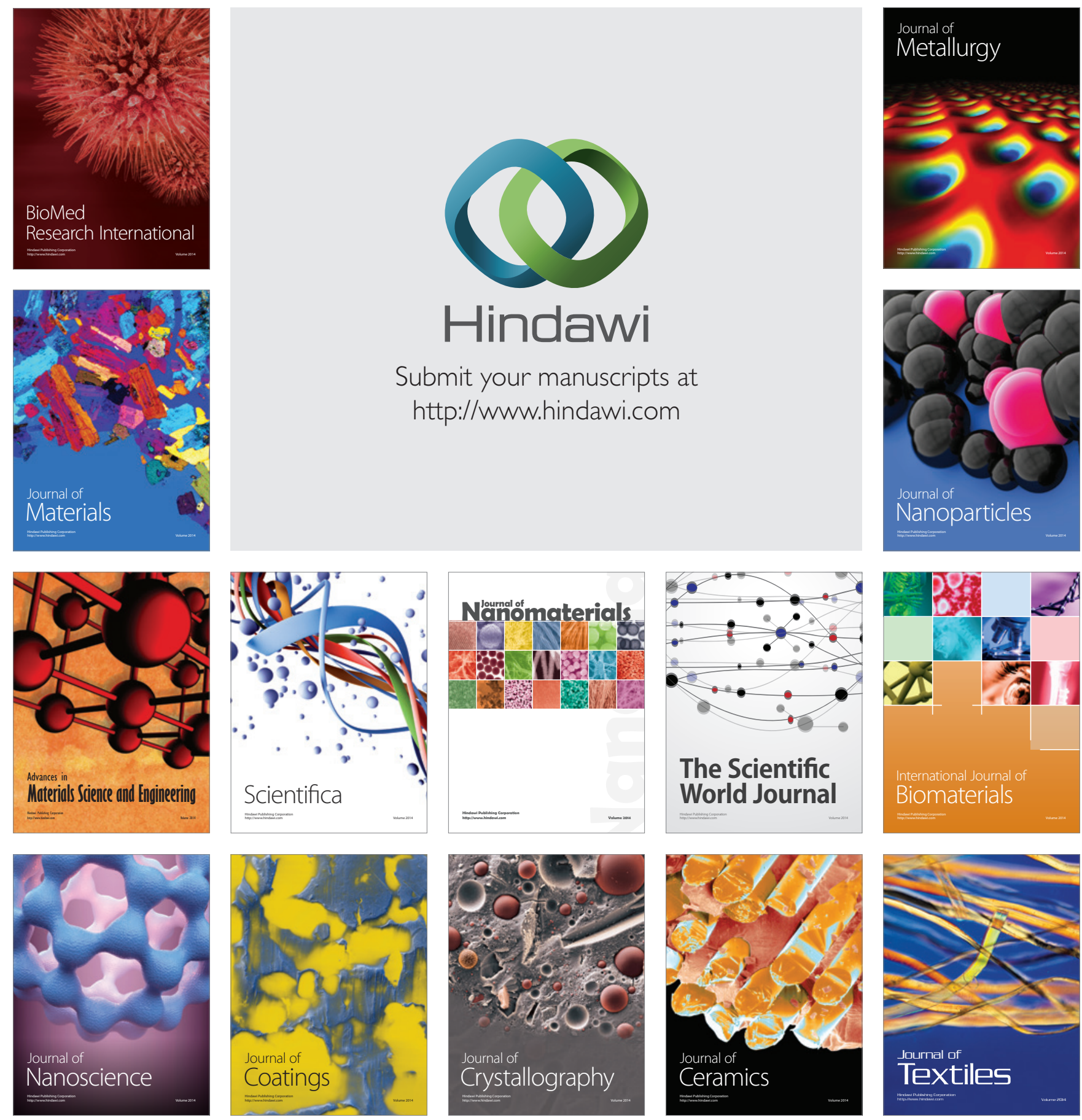